\title{
THE CLINICAL PROFILE OF DENGUE PATIENTS IN CHILDREN
}

\section{${ }^{1}$ Dr Poonam Meena, ${ }^{2 *}$ Dr Satish Meena, ${ }^{3}$ Dr Ashok Meena, ${ }^{4}$ Dr Kailash Meena}

${ }^{1}$ Medical Officer Government Hospital Dausa

${ }^{2}$ FNB Fellow, Pediatric Hematology and Oncology, Apollo Hospital Chennai

${ }^{3}$ Medical Officer Government Hospital Dausa

${ }^{4}$ Senior Professor, Department of Paeditrics, S M S Medical College Jaipur

Article Info: Received 13 October 2021; Accepted 28 November 2021

DOI: https://doi.org/10.32553/ijmbs.v5i12.2328

Corresponding author: Dr Satish Meena

Conflict of interest: No conflict of interest.

\section{Abstract}

Background: To study the clinical profile of dengue in children

Methods: The hospital based study was conducted on patients presenting to paediatric hospital, who fulfilled inclusion and exclusion criteria.

Results: Based on the symptoms, the most common symptoms noticed were fever $94.00 \%$ followed by myalgia $85.00 \%$ decreased appetite $83 \%$, retroorbital pain in $84.0 \%$ and vomiting $81.00 \%$

Conclusion: It concluded that common symptoms observed were fever, myalgia, decreased appetite and headache The common complications presented were hepatic dysfunction and shock with no mortality indicating the presence of less virulent organisms..

Keywords: Dengue, Complication, Shock

\section{Introduction}

India is one of the seven countries in the South-East Asia region regularly reporting incidence of dengue outbreaks due to its high incidence which constantly threatens the health care system. The first confirmed case of dengue fever in India dates back to 1940s, and since then more and more new cases have been reported which mostly occurs in epidemics often resulting in high morbidity and mortality. $\frac{1,2}{}$

Fatal form of the disease, severe dengue fever has been reported in India from time to time in Kolkata, Delhi, and Chennai. All the four serotypes of the virus have been in circulation and reported in Tamil Nadu. During all these epidemics infection occurred in all the age groups and more so in adults in the age group of $16-60$ years. ${ }^{3,4}$

\section{Material and Methods}

Study Design:Hospital-based cross-sectional study.

\section{Inclusion criteria}

- Children with age group of 0-18 years. Admitted with symptoms of dengue fever based on WHO criteria. NS1 antigen and IgM dengue antibody positive, cases by ELISA technique.

\section{Exclusion criteria}

- Children with IgG dengue antibody positive.

- Children with enteric fever and malaria

\section{Observations}

Table 1: Distribution of Cases According to Age Group (years)

\begin{tabular}{|l|l|}
\hline Variable & Dengue Positive(n=100) \\
\hline Age & $10.51 \pm 2.16$ \\
\hline Male : Female & $64: 36$ \\
\hline
\end{tabular}

Mean age was $10.51 \pm 2.16$ year in dengue positive cases.

Table 2: Clinical profile

\begin{tabular}{|l|l|l|}
\hline Clinical profile & No of cases & Percentage \\
\hline Fever & 94 & 94.00 \\
\hline Myalgia & 85 & 85.00 \\
\hline Retroorbital pain & 84 & 84.00 \\
\hline Decreased appetite & 83 & 83.00 \\
\hline Vomiting & 81 & 81.00 \\
\hline Headache & 80 & 80.00 \\
\hline Pain abdomen & 80 & 80.00 \\
\hline
\end{tabular}




\begin{tabular}{|l|l|l|}
\hline Abdominal distension & 67 & 67.00 \\
\hline
\end{tabular}

Based on the symptoms, the most common symptoms noticed were fever $94.00 \%$ followed by myalgia $85.00 \%$ decreased appetite $83 \%$, retroorbital pain in $84.0 \%$ and vomiting $81.00 \%$

Table 3: Distribution of Cases According to Complication

\begin{tabular}{|l|c|c|}
\hline Complication & No of cases & Percentage \\
\hline Bleeding & 52 & 52.00 \\
\hline Myocarditis & 3 & 3.00 \\
\hline Shock & 34 & 34.00 \\
\hline Convulsion & 1 & 1.00 \\
\hline No Complication & 11 & 11.00 \\
\hline Total & 100 & 100.00 \\
\hline
\end{tabular}

According to complications, in dengue positive cases, bleeding was the most common complication seen in $52.00 \%$ cases while shock, myocarditis, and convulsion were present in $34.00 \%, 3.00 \%$ and $1.00 \%$ of cases respectively.

\section{Discussion}

Dengue is a major international health concern that is prevalent in tropical and sub-tropical countries. Since the first confirmed case of dengue in India, during the 1940s, intermittent reports from Delhi, Ludhiana, Mangalore, Vellore and from other states have been published. The diagnosis is by clinical profile but they can present with varied manifestation ${ }^{5-6}$.

There is a steady increase in the outbreak of dengue fever over the years and so among children. This is due to the rapid urbanization with unplanned construction activities and poor sanitation facilities contributing fertile breeding grounds for mosquitoes. Due to an increase in the awareness among health care professionals following the initial epidemic and the availability of diagnostic tests have contributed to the increased diagnosis ${ }^{7}$.

A outbreak of dengue fever during pre-monsoon and monsoon season reported due to stagnation of water after a bouts of rainfall which facilitate vector breeding. This highlight the preventive measures against dengue fever should be taken during water stagnation periods after the initial bouts of rainfall and at the end of monsoon.

In our study mean age was $10.51 \pm 2.16$ year in dengue positive cases. This may be due to out-door activities of these children, where chances of getting bitten by mosquitoes are more. Similar finding was observed in other studies $^{8-10}$.

Boys were slightly more affected then girls were also observed by Selvan et $\mathrm{a}^{10}$ and Sahana et $\mathrm{al}^{9}$ and similar pattern was seen in the retrospective analysis of the 2006 North Indian Dengue outbreak ${ }^{14}$. This may be due to outdoor activities of these children, where chances of getting bitten by mosquitoes are more.
According to complications, According to complications, in dengue positive cases, bleeding was the most common complication seen in $51.00 \%$ cases while shock, myocarditis, and convulsion were present in $34.00 \%$, $3.00 \%$ and $1.00 \%$ of cases respectively.

Raj et al ${ }^{11}$ observed that shock was the most common and difficult to treat complication despite appropriate fluid management in accordance with WHO regimen. 20(10.2\%) children had shock, of which 7 were refractory to fluid therapy and blood products (whole blood, packed cell volume, FFP) given as indicated.

\section{Conclusion}

It concluded that common symptoms observed were fever, myalgia, decreased appetite and headache The common complications presented were hepatic dysfunction and shock with no mortality indicating the presence of less virulent organisms..

\section{References}

1. Tripathi P, Kumar R, Tripathi S, Tambe J, Venkatesh V. Descriptive epidemiology of dengue transmission in Utta Pradesh. Ind Pediatr 2008; 45(4):315.

2. Halstead SB. More dengue, more questions. Emerg Infect Dis 2005; 11(5):740-41.

3. Ramos MM, Tomashek KM, Arguello DF, Luxemburger C, Quinones L et al. Early clinical features of dengue infection in Puerto Rico. Transactions of the Royal Society of Trop Med Hygiene 2009; 103(9):878-84.

4. Chaudhary R, Khetan D, Sinha S, Sinha P, Sonker A et al. Transfusion support to dengue patients in a hospital base blood transfusion service in North India. Transfusion and Apheresis Sci 2006;3 5(3);239-44.

5. Padibidri VS, Adhikari $\mathrm{P}$, Thakare JP, Ilkal MA, Joshi GD, Pereira P, et al. The 1993 epidemic of dengue fever in Mangalore, Karnataka State, India. Southeast Asian J Trop Med Public Health. 1995;26:699-704. 
6. Cherian T, Ponnuraj E, Kuruvilla T, Kirubakaran C, John TJ, Raghupathy P. An epidemic of dengue hemorrhagic fever and dengue shock syndrome in and around Vellore. Indian J Med Res. 1994;100:516.

7. Gubler DJ. Dengue and dengue hemorrhagic fever. Clin Microbiol Rev. 1998;11:480-96.

8. Mittal H, Faridi MM, Arora SK, Patil R. Clinicohematological profile and platelet trends in children with dengue during 2010 epidemic in north India. Indian J Pediatr. 2012;79:467-71.
9. Sahana KS, Sujatha R. Clinical profile of dengue among children according to revised WHO classification: analysis of a 2012 outbreak from Southern India. Indian J Pediatr 2015;82:109-13.

10. Selvan T, Nagaraj MV, Saravanan P, Somashekar. A study of clinical profile of dengue fever in children. Int J Contemp Pediatr 2017;4:534-7.

11. Raj AS, Munshi S, Shah BH. A study on clinical presentation of dengue fever in Children. IJMSR, 2016; 2272-8. 